\title{
The Administration of Xultophy for Diabetic Patients on Hemodialysis
}

Fujikawa $\mathrm{T}^{1}$, Kato $\mathrm{Y}^{1}$, Bando $\mathrm{H}^{1,2^{*}}$, Kakutani $\mathrm{H}^{1}$, Kawata $\mathrm{T}^{1}$, Yamamoto $\mathrm{M}^{1}$, Wada $\mathrm{K}^{1}$, Ishikura $\mathrm{K}^{1}$, Shirai $\mathrm{Y}^{1}$, Narutaki $\mathrm{M}^{1}$, Matsuzaki $\mathrm{S}^{1}$, Waka $\mathrm{S}^{1}$

${ }^{1}$ Kanaiso Hospital, Tokushima, Japan

${ }^{2}$ Tokushima University / Medical Research, Tokushima, Japan

Corresponding Author: Hiroshi BANDO, MD, PhD, FACP ${ }^{\text {ORCID ID }}$

Address: Tokushima University /Medical Research, Nakashowa 1-61, Tokushima 770-0943 Japan; E-mail: pianomed@bronze.ocn.ne.jp

Received date: 14 September 2020; Accepted date: 10 October 2020; Published date: 20 October 2020

Citation: Fujikawa T, Kato Y, Bando H, Kakutani H, Kawata T, Yamamoto M, Wada K, Ishikura K, Shirai Y, Narutaki M, Matsuzaki S, Waka S. The Administration of Xultophy for Diabetic Patients on Hemodialysis. Diab Res Open Access. 2020 Oct 20;2(3):72-78.

Copyright (C) 2020 Fujikawa T, Kato Y, Bando H, Kakutani H, Kawata T, Yamamoto M, Wada K, Ishikura K, Shirai Y, Narutaki M, Matsuzaki S, Waka S. This is an open-access article distributed under the Creative Commons Attribution License, which permits unrestricted use, distribution, and reproduction in any medium, provided the original work is properly cited.

\begin{abstract}
Background: Recent diabetic treatments include Insulin Degludec/liraglutide (IDeg/Lira, Xultophy) in clinical practice. Authors have continued clinical research concerning diabetes, chronic renal failure, dialysis, and others.

Subjects and Methods: Ten patients with type 2 diabetes mellitus (T2DM) undergoing hemodialysis were investigated. They showed that ages $74.5 \pm 5.9$ years, $\mathrm{M} / \mathrm{F}=6 / 4$, BMI $21.1 \pm 3.8 \mathrm{~kg} / \mathrm{m}^{2}$, hemodialysis duration $8.1 \pm 5.7$ years. At the beginning, fundamental data were Cre $8.2 \pm 1.9 \mathrm{mg} / \mathrm{dL}$, HbA1c $6.5 \pm 0.8 \%$. Xultophy was started on 5-12 doses and continued for 6 months with the same or 1-4 increased doses for better glycemic variability.

Results: Out of 10 subjects, the changes in HbA1c showed a decrease in 7 , stable in 2, and an increase in 1. HbA1c value was $6.2 \pm 0.8 \%$ in average at 6 months. There were no remarkable adverse effects by Xultophy for 6 months.

Discussion and Conclusion: Xultophy was started at 5-12 doses, which were remarkably lower doses than usual doses with satisfactory efficacy. One of the reasons may be from the characteristic of the patients, who were diabetic with undergoing hemodialysis. Another factor is possibly from liraglutide, which has hepatic clearance with potential vascular protective effects. These results are expected to become reference data for future research.
\end{abstract}

\section{Keywords}

Xultophy, Insulin Degludec/Liraglutide (IDegLira), Type 2 Diabetes Mellitus, Hemodialysis

\section{Abbreviation}

OHAs: Oral Hypoglycemic Agents; ASCVD: Atherosclerotic Cardiovascular Disease; GLP-1 RA: Glucagon-Like Protein-1 Receptor Agonist; T2DM: Type 2 Diabetes Mellitus; JLCDPA: Japan LCD Promotion Association 
Citation: Fujikawa T, Kato Y, Bando H, Kakutani H, Kawata T, Yamamoto M, Wada K, Ishikura K, Shirai Y, Narutaki M, Matsuzaki S, Waka S. The Administration of Xultophy for Diabetic Patients on Hemodialysis. Diab Res Open Access. 2020 Oct 20;2(3):72-78.

\section{Original Article}

\section{Introduction}

As to the fundamental therapy for T2DM, comprehensive lifestyle changes such as meal, weight control, and exercise remain as first-line treatment. However, most patients require dual or triple oral hypoglycemic agents (OHAs) to keep adequate glucose variability $[1,2]$. There are some main guidelines concerning diabetic management, such as the 2019 consensus report of the European Association for the Study of Diabetes (EASD) and the American Diabetes Association (ADA), and 2020 ADA guidelines. They recommend the stepwise addition of several kinds of agents for diabetes. In such cases, some aspects should be considered, including drug characteristics, administration route, costs, adverse effects, patient preference, as well as present comorbidities such as heart failure (HF), atherosclerotic cardiovascular disease (ASCVD), and chronic kidney disease (CKD) $[1,2]$.

Co-administration of a glucagon-like protein-1 receptor agonist (GLP-1 RA) and long-acting basal insulin as a treatment of type 2 diabetes mellitus (T2DM) to achieve improved glycemic control in patients with T2DM is based on a solid understanding of the complementary physiological mechanisms of the actions of both agents [3]. Ample clinical data support combining these agents for the treatment of T2DM. It means an approach which is endorsed as a third-line treatment in the consensus report by the ADA and EASD on the management of hyperglycemia in T2DM [4].

From some large cardiovascular outcome trials (CVOTs), recent diabetic guidelines showed the recommendation of sodium-glucose cotransporter 2 inhibitor (SGLT2i) or GLP-1RA for patients with highrisk states of kidney disease CKD, HF, ASCVD, regardless of the HbA1c values [1,2]. The combined therapy of basal insulin plus a GLP-1RA has been one beneficial method to strengthen the effective treatment with injectable agents. By both complementary actions, combined agents can improve glucose variability, associated with the reduction of adverse effects $[5,6]$. From these, Insulin Degludec/liraglutide (IDegLira, Xultophy $^{\mathrm{TM}}$ ) has been a fixed-ratio combination of long-acting basal insulin analog and also GLP-1RA for recent therapy of T2DM $[7,8]$.

Our research group has been involved in clinical practice especially concerning diabetes, chronic renal failure, and hemodialysis. As regard to diabetes, authors and collaborators have developed research concerning the comparisons of low carbohydrate diet (LCD), calorie restriction (CR), meal tolerance test (MTT), increased ketone bodies, continuous glucose monitoring (CGM), and so on [9,10]. Furthermore, we established the Japan LCD Promotion Association (JLCDPA) and have continued various activities through JLCDPA such as seminars for LCD, medical societies, textbooks, journals, and newsletters through the internet $[11,12]$.

Furthermore, for CKD and hemodialysis, we reported several studies concerning nerve conduction velocity (NCV), diabetic kidney disease (DKD), carnitine, and others for patients with chronic renal failure and hemodialysis [13,14,15]. Through our clinical practice, there was a case with beneficial efficacy with the treatment of Xultophy [16]. Successively, our hemodialysis team has studied the effect of Xultophy for hemodialysis patients, and the results and discussion would be described in this study.

\section{Subjects and Methods \\ Subjects:}

Subjects in this study included ten patients with T2DM and chronic renal failure (CRF) who have been treated by hemodialysis three times a week. The basic data of the subjects are shown in Table-1.

\section{Methods:}

The purpose of the study was to administer Xultophy, evaluate the results, and to discuss the clinical significance. The patients were treated before by Dulaglutide or Degludec with stable diabetic state and stable HbAic values. The changes in HbAic values were shown in Fig-1. In this figure, \#1 - \#10 with colored numbers mean case $1-10$ at the right side, and $\#_{5}-\# 12$ with black numbers mean the starting doses of Xultophy at o months at the left side. The doses of them were the same or increased 1-4 doses for 6 months. The changes in HbAic on o, 2, 4, 6 months 
Citation: Fujikawa T, Kato Y, Bando H, Kakutani H, Kawata T, Yamamoto M, Wada K, Ishikura K, Shirai Y, Narutaki M, Matsuzaki S, Waka S. The Administration of Xultophy for Diabetic Patients on Hemodialysis. Diab Res Open Access. 2020 Oct 20;2(3):72-78.

\section{Original Article}

are summarized in Fig-1.

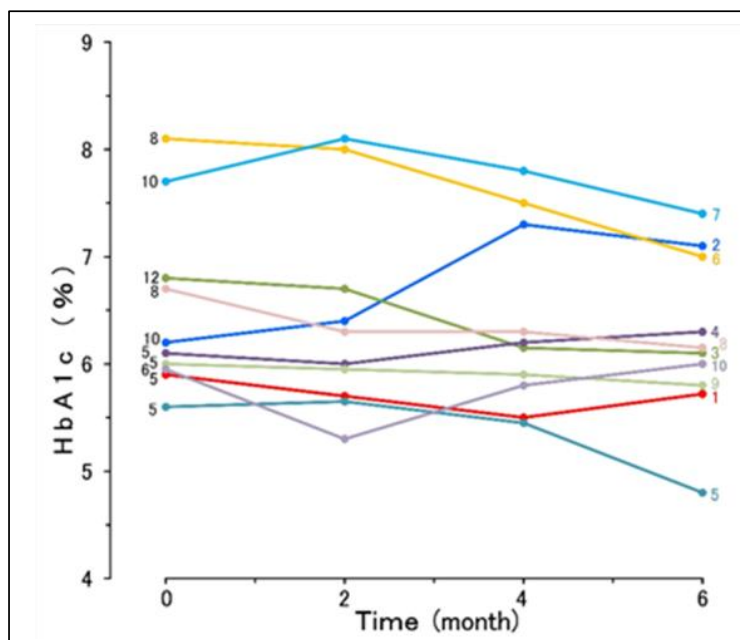

Fig-1: Changes in HbAic of subjects for 6 months

Subjects include 10 diabetic patients with hemodialysis, in which \#1 - \#10 with colored numbers mean case 1 - 10 at right side. In contrast, \#5 - \#12 with black numbers mean the starting doses of Xultophy at o months at left side.

\section{Xultophy:}

For the current study, Xultophy includes long-acting insulin and GLP-1 RA. One unit of Xultophy ${ }^{\circledR}(100 / 3.6)$ contains 1 unit of insulin degludec associated with $0.036 \mathrm{mg}$ of liraglutide [17]. Consequently, Xultophy can be injected from 10-50 units. In the case of Xultophy, they use 10-50 doses instead of 10-50 units.

The Xultophy ${ }^{\circledR}$ pen has been prevalent, which is prefilled by 300 units of Xultophy ${ }^{\circledR}$ 100/3.6 (300 unit's insulin degludec/10.8 mg liraglutide). As for the safety mechanism, it does not have a push-button extension, or the dose button does not move while dialing the doses [17]. The method is a once-daily regimen, and it usually has less weight gain or hypoglycemia associated with increased insulin regimens. In addition, Xultophy shows the benefit of reduced gastrointestinal (GI) side effects in comparison with those of GLP-1 RA alone [17,18].

\begin{tabular}{|c|c|c|c|c|c|c|c|c|c|c|}
\hline \multicolumn{11}{|c|}{ Table-1: List of the Patients with Hemodialysis } \\
\hline $\begin{array}{l}\text { Case } \\
\text { (No) }\end{array}$ & $\begin{array}{c}\text { Age } \\
\text { (Years) }\end{array}$ & $\begin{array}{c}\text { Sex } \\
(M / F)\end{array}$ & $\begin{array}{c}\text { Height } \\
\text { (cm) }\end{array}$ & $\begin{array}{c}\text { Weight } \\
\text { (kg) }\end{array}$ & $\begin{array}{c}\text { BMI } \\
\left(\mathrm{kg} / \mathrm{m}^{2}\right)\end{array}$ & $\begin{array}{c}\text { HD } \\
\text { (Years) }\end{array}$ & $\begin{array}{l}\text { Before Tx } \\
\text { Injection }\end{array}$ & $\begin{array}{c}\text { Cre } \\
(\mathrm{mg} / \mathrm{dL})\end{array}$ & $\begin{array}{c}\text { HbA1c- } \\
\text { om } \\
(\%)\end{array}$ & $\begin{array}{l}\text { Xultophy } \\
\text { (Doses) }\end{array}$ \\
\hline 1 & 69 & M & 162 & 58.0 & 22.1 & 5 & Dulaglutide & $9 \cdot 9$ & $5 \cdot 9$ & 5 \\
\hline 2 & 78 & $\mathrm{~F}$ & 150 & $39 \cdot 5$ & 17.6 & 3 & Dulaglutide & 6.9 & 6.2 & 10 \\
\hline 3 & 68 & M & 172 & 66.0 & 22.3 & 10 & Dulaglutide & 10.4 & 6.8 & 12 \\
\hline 4 & 78 & M & 155 & 50.5 & 21.0 & 9 & Dulaglutide & 6.6 & 6.1 & 5 \\
\hline 5 & 88 & $\mathrm{~F}$ & 146 & 36.0 & 16.9 & 11 & Dulaglutide & 6.5 & 5.6 & 5 \\
\hline 6 & 70 & M & 160 & 73.5 & 28.7 & 3 & Dulaglutide & 10.5 & 8.1 & 8 \\
\hline 7 & 71 & M & 165 & 53.0 & 19.5 & 8 & Dulaglutide & 8.5 & $7 \cdot 7$ & 10 \\
\hline 8 & 74 & $\mathrm{~F}$ & 155 & 61.0 & 25.4 & 7 & Dulaglutide & $9 \cdot 3$ & 6.7 & 8 \\
\hline 9 & 75 & M & 171 & 48.5 & 16.6 & 3 & Dulaglutide & 8.4 & 6.0 & 5 \\
\hline 10 & 74 & $\mathrm{~F}$ & 143 & 42.0 & 20.5 & 22 & Degludec & 4.8 & 6.0 & 6 \\
\hline Mean & 74.5 & & 157.9 & 52.8 & 21.1 & 8.1 & & 8.2 & 6.5 & $7 \cdot 4$ \\
\hline SD & 5.9 & & $9 \cdot 9$ & 12.0 & 3.8 & $5 \cdot 7$ & & 1.9 & 0.8 & 2.6 \\
\hline \multicolumn{11}{|c|}{ i) As previous treatment of Dulaglutide, it was administered xx mg once per week } \\
\hline \multicolumn{11}{|c|}{ ii) As previous treatment of Degludec, it was administered 6 units once per day } \\
\hline \multicolumn{11}{|c|}{ iii) Before starting Xultophy, values of creatinine and HbAic are described } \\
\hline & iv) On st & ng tre & nent of & Itophy, tl & first dos & are descr & ed in the tabl & & & \\
\hline
\end{tabular}




\section{Results}

In the current study, the results for 10 cases of hemodialysis are shown in Table-1. The values of mean \pm standard deviation (SD) were as follows: ages $74.5 \pm 5.9$ years, $\mathrm{M} / \mathrm{F}=6 / 4$, BMI $21.1 \pm 3.8 \mathrm{~kg} / \mathrm{m}^{2}$, hemodialysis duration $8.1 \pm 5.7$ years. The average value of serum creatinine before hemodialysis at 0 months was $8.2 \pm 1.9 \mathrm{mg} / \mathrm{dL}$. By the administration of Xultophy, the changes in HbAic values in o, 2, 4, 6 months for 10 cases were described in Fig-1. At 6 months, 7 out of 10 showed a decreasing tendency of HbA1c, 2 showed no changes, and 1 showed an increasing tendency.

\section{Discussion}

The treatment of diabetes has changed in recent years. Efficient insulin preparations have emerged, and GLP-1 RA preparations have been introduced to clinical practice. Subsequently, a combination of long-acting insulin and GLP-1 RA has been developed.

Insulin Degludec and liraglutide are combined and it was approved for T2DM patients by the regulatory agency [19]. It was IDegLira, which is called Xultophy 100/3.6, by Novo Nordisk, Denmark. It has been combined as Fixed-Ratio Combinations (FRC) of basal insulin and long-acting GLP-1 analog for once-daily subcutaneous injection for T2DM [20-22]. Its efficacy and safety of IDegLira have been evaluated by the DUAL I-IX series of randomized clinical trials (RCTs). They compared the new agent IDegLira use to other long-acting new generation basal insulin and longacting GLP-1 RA analog [23-25].

From these results, IDegLira was recognized to be superior to other agents provided alone for reducing HbAic values. Furthermore, IDegLira has shown weight reduction rather than weight increase, reduced episodes of hypoglycemia, reduced insulin-dose requirement, and higher rates of achieving less than $7 \%$ as HbA1c target [19-25]. These benefits were revealed in DUAL RCTs studies, and the beneficial potential of IDegLira FRC was expected for increasing adherence to diabetic treatment.
IDegLira has been produced as a fixed-ratio combination (FRC) of the basal degludec and liraglutide, GLP-1 agonist [26]. The beneficial points of combined agents are described [27]. From several data of DUAL results and post hoc analyses, some cases have shown remarkable efficacy for IDegLira [28]. Refraining from more complex injectable treatments, patients with renal insufficiency are one of the most adequate and effective cases, for whom therapeutic options are rather limited [28]. There is another research group of IDegLira, which is the European Xultophy Treatment Retrospective Audit (EXTRA) [29]. From the data of EXTRA real-world evidence study, better clinical outcomes and cost-effectiveness were observed. In detail, IDegLira vs multiple daily insulin injections (MDI) showed EUR 3013 vs. 6890 per quality-adjusted life-year (QALY) gained, respectively.

In this study, we have tried the administration of IDegLira (Xultophy) in 10 hemodialysis patients and examined the changes in HbA1c at o, 2, 4, and 6 months. The protocol was successful with no particular problems, unexpected symptoms, or signs. Conventionally, it is said that no remarkable adverse effects are observed in the administration of Xultophy [26]. At o month, there are 5 cases with lower HbAic (5.6\%-6.1\%), for which 5-6 doses of Xultophy were administered. In contrast, there are 5 cases with higher HbA1c (6.3\%-8.1\%), for which 8-12 doses of Xultophy were administered. At 6 months, 7 out of 10 showed a decreasing tendency of HbA1c, 2 showed no changes, and 1 showed an increasing tendency. Among them, the two cases with higher HbA1c at o months (cases 6 and 7) showed a remarkable reduction. It was reported that the decrease of HbAic was larger in the cases where the pre-level of HbA1c was rather higher.

As to the characteristics of the subjects in the current study, they are diabetic and undergoing hemodialysis due to chronic renal failure (CRF). Consequently, the relationship between renal dysfunction and GLP-1 RA is important. There are several kinds of GLP-1 Ras so far. Among them, lixisenatide and exenatide are predominantly cleared through the kidney [30]. The dose of exenatide is not recommended to be increased in the diabetic case with 
eGFR of $30-60 \mathrm{~mL} / \mathrm{min} / 1.73 \mathrm{~m} 2$. In contrast, dulaglutide and liraglutide have predominantly hepatic clearance. GLP-1 RAs have been recognized to show direct and indirect renal protective effects and some hepatic health benefits (Grade A; EL 1). When these are given to diabetic cases with renal impairment, it is necessary to consider the caution of gastrointestinal adverse effects, which is Grade D; EL 4 [30]. Liraglutide has shown potential vascular protective effects through some mechanism incompletely understood. From the study of T2DM rats, liraglutide may ameliorate vascular endothelial dysfunction via anti-oxidative and activated endothelial oxide synthase (eNOS) [31].

This study has limitations. The subjects are patients undergoing hemodialysis due to diabetic renal failure, and their background seems to be highly heterogeneous. The number of cases was small, including mild to severe cases, and the value of HbA1c was distributed widely. The initial dose of Xultophy is reported to be 16 doses in Europe and North American countries, and 10 doses in Japan. In the current study, Xultophy was started with 5-12 doses, which were remarkably lower doses than usual doses with stable clinical course. One of the reasons may be from the characteristic of the patients, who were diabetic with undergoing hemodialysis. The provided doses of Xultophy were not so increased for 6 months. The doses will be increased according to the patient's situation for better glucose variability after 6 months. For further investigation of the effect of IDegLira in hemodialysis patients, detailed studies will be required including adequate protocols with some groups and applicable biomarkers.

In summary, this pilot study showed the efficacy of IDegLira for diabetic patients with hemodialysis. Authors expect that this report would become some fundamental and reference data for clinical research in the future.

\section{Ethical Considerations}

The current study was basically conducted in compliance with the ethical principles. It was along with the Declaration of Helsinki. In addition, some commentary was present for the Ethical Guidelines for
Research in the medical research for the human and in the conduction of the Good Clinical Practice (GCP). Regarding the protection of human rights, some ongoing consideration was present. Further, there was "Ethical Guidelines for Epidemiology Research" applied for the related guideline. Those principles were from Japan by the Ministry of Health, Labor and Welfare, and the Ministry of Education, Culture, Sports, Science, and Technology.

As to this study, authors have taken the written informed consent from all subjects. Moreover, we established the ethical committee in Kanaiso hospital for clinical research. The ethical committee includes the president of the hospital, the director of the Pharmacology Department, the directors of the nursing and administration departments, and some experts in the legal, medical, and pharmaceutical specialties. The members discussed satisfactory about the research content and agreed that this study would be adequate without any problems.

\section{Acknowledgement}

The authors would like to express our gratitude for related all people concerning this research.

\section{Funding}

None of the authors listed for this publication have any financial support.

\section{Conflicts of Interest}

All authors have read and approved the final version of the manuscript. The authors have no conflicts of interest to declare.

\section{References}

[1] American Diabetes Association. 9. Pharmacologic Approaches to Glycemic Treatment: Standards of Medical Care in Diabetes-2020. Diabetes Care. 2020 Jan;43(Suppl 1):S98-10. [PMID: 31862752]

[2] Buse JB, Wexler DJ, Tsapas A, Rossing P, Mingrone G, Mathieu C, D'Alessio DA, Davies MJ. 2019 Update to: Management of Hyperglycemia in Type 2 Diabetes, 2018. A Consensus Report by the American Diabetes Association (ADA) and the European Association for the Study of Diabetes (EASD). Diabetes Care. 2020 
Citation: Fujikawa T, Kato Y, Bando H, Kakutani H, Kawata T, Yamamoto M, Wada K, Ishikura K, Shirai Y, Narutaki M, Matsuzaki S, Waka S. The Administration of Xultophy for Diabetic Patients on Hemodialysis. Diab Res Open Access. 2020 Oct 20;2(3):72-78.

Original Article

Feb;43(2):487-93. [PMID: 31857443]

[3] Berlie H, Hurren KM, Pinelli NR. Glucagon-like peptide-1 receptor agonists as add-on therapy to basal insulin in patients with type 2 diabetes: a systematic review. Diabetes Metab Syndr Obes. 2012;5:165-74. [PMID: 22826635]

[4] Davies MJ, D'Alessio DA, Fradkin J, Kernan WN, Mathieu C, Mingrone G, Rossing P, Tsapas A, Wexler DJ, Buse JB. Management of Hyperglycemia in Type 2 Diabetes, 2018. A Consensus Report by the American Diabetes Association (ADA) and the European Association for the Study of Diabetes (EASD). Diabetes Care. 2018 Dec;41(12):2669-701. [PMID: 30291106]

[5] Liakopoulou P, Liakos A, Vasilakou D, Athanasiadou E, Bekiari E, Kazakos K, Tsapas A. Fixed ratio combinations of glucagon like peptide 1 receptor agonists with basal insulin: a systematic review and meta-analysis. Endocrine. 2017 Jun;56(3):485-94. [PMID: 28401444]

[6] Perreault L, Rodbard H, Valentine V, Johnson E. Optimizing Fixed-Ratio Combination Therapy in Type 2 Diabetes. Adv Ther. 2019 Feb;36(2):265-77. [PMID: 30610613]

[7] Xultophy (insulin degludec/liraglutide): EU summary of product characteristics. Bagsvaerd (Denmark): Novo nordisk A/S; 2019.

[8] Xultophy 100/3.6 (insulin degludec and liraglutide) injection, solution: US prescribing information. Bagsvaerd (Denmark): Novo Nordisk A/S; 2019.

[9] Ebe K, Ebe Y, Yokota S, Matsumoto T, Hashimoto M, Sakai Y. Low Carbohydrate diet (LCD) treated for three cases as diabetic diet therapy. Kyoto Medical Association Journal. 2004;51:125-29.

[10] Bando H, Muneta T, Bando M, Yonei Y. Effect of low carbohydrate diet on type 2 diabetic patients and usefulness of M-value. Diabetes Res Open J. 2017 Feb 13;3(1):9-16.

[11] Kato Y, Bando H, Yamashita H, Yada S, Tokuhara S, Tokuhara H, Mutsuda T. Seasonal changes in HbAic values from young to elderly diabetic patients. J Diabetes Metab Disord Control. 2019 Aug 30;6(3):8992.

[12] Muneta T, Kawaguchi E, Nagai Y, Matsumoto M, Ebe K, Watanabe H, Bando H. Ketone body elevation in placenta, umbilical cord, newborn and mother in normal delivery. Glycat Stress Res. 2016 Sep 30;3(3):133-40.
[13] Fujikawa T, Kato Y, Bando H, Narutaki M, Yamamoto M, Kakutani H, Shirai Y, Ishikura K, Kusunoki K, Tanaka S, Kawata T. Investigation of Nerve Conduction in Patients with Diabetes and/or Hemodialysis. SF J Chro Dis. 2017 Dec 22;1(1).

[14] Kato Y, Bando H, Matsuzaki S, Waka S. Current topics of possible pharmacotherapy for chronic kidney disease (CKD) and diabetes. Pharm Pharmacol Int J. 2020 Apr 15;8(2):87-89.

[15] Kakutani H, Kato Y, Fujikawa T, Kawata T, Yamamoto M, Wada K, Ishikura K, Shirai Y, Narutaki M, Kanazawa S, Matsuzaki S. Carnitine for Body Composition in Hemodialysis Patients. Edel J Biomed Res Rev. 2020 Feb 27;2(1):6-9.

[16] Kato Y, Bando H, Yamashita H, Yada S, Tokuhara S, Tokuhara H, Mutsuda T. Impressive clinical course of diabetic patient with various medical problems and remarkable improvement by insulin degludec and liraglutide (Xultophy). MOJ Clin Med Case Rep. 2020 Apr 30;10(2):48-51.

[17] Homepage of Xultophy ${ }^{\circledR}$.

https://www.xultophy10036pro.com/

[18] Melzer-Cohen C, Chodick G, Naftelberg S, Shehadeh N, Karasik A. Metabolic Control and Adherence to Therapy in Type 2 Diabetes Mellitus Patients Using IDegLira in a Real-World Setting. Diabetes Ther. 2020 Jan;11(1):185-96. [PMID: 31808132]

[19] Lingvay I, Pérez Manghi F, García-Hernández P, Norwood P, Lehmann L, Tarp-Johansen MJ, Buse JB; DUAL V Investigators. Effect of Insulin Glargine Uptitration vs Insulin Degludec/Liraglutide on Glycated Hemoglobin Levels in Patients With Uncontrolled Type 2 Diabetes: The DUAL V Randomized Clinical Trial. JAMA. 2016 Mar 1;315(9):898-907. [PMID: 26934259] [20] Linjawi S, Bode BW, Chaykin LB, Courrèges JP, Handelsman Y, Lehmann LM, Mishra A, Simpson RW. The Efficacy of IDegLira (Insulin Degludec/Liraglutide Combination) in Adults with Type 2 Diabetes Inadequately Controlled with a GLP-1 Receptor Agonist and Oral Therapy: DUAL III Randomized Clinical Trial. Diabetes Ther. 2017 Feb;8(1):101-14. [PMID: 27943107]

[21] Rodbard HW, Bode BW, Harris SB, Rose L, Lehmann L, Jarlov H, Thurman J; Dual Action of Liraglutide and insulin degludec (DUAL) IV trial investigators. Safety and efficacy of insulin 
Citation: Fujikawa T, Kato Y, Bando H, Kakutani H, Kawata T, Yamamoto M, Wada K, Ishikura K, Shirai Y, Narutaki M, Matsuzaki S, Waka S. The Administration of Xultophy for Diabetic Patients on Hemodialysis. Diab Res Open Access. 2020 Oct 20;2(3):72-78.

\section{Original Article}

degludec/liraglutide (IDegLira) added to sulphonylurea alone or to sulphonylurea and metformin in insulinnaïve people with Type 2 diabetes: the DUAL IV trial. Diabet Med. 2017 Feb;34(2):189-96. [PMID: 27589252]

[22] Harris SB, Kocsis G, Prager R, Ridge T, Chandarana K, Halladin N, Jabbour S. Safety and efficacy of IDegLira titrated once weekly versus twice weekly in patients with type 2 diabetes uncontrolled on oral antidiabetic drugs: DUAL VI randomized clinical trial. Diabetes Obes Metab. 2017 Jun;19(6):858-65. [PMID: 28124817]

[23] Billings LK, Doshi A, Gouet D, Oviedo A, Rodbard HW, Tentolouris N, Grøn R, Halladin N, Jodar E. Efficacy and Safety of IDegLira Versus Basal-Bolus Insulin Therapy in Patients With Type 2 Diabetes Uncontrolled on Metformin and Basal Insulin: The DUAL VII Randomized Clinical Trial. Diabetes Care. 2018 May;41(5):1009-16. [PMID: 29483185]

[24] Philis-Tsimikas A, Billings LK, Busch R, Portillo CM, Sahay R, Halladin N, Eggert S, Begtrup K, Harris S. Superior efficacy of insulin degludec/liraglutide versus insulin glargine U10o as add-on to sodiumglucose co-transporter-2 inhibitor therapy: A randomized clinical trial in people with uncontrolled type 2 diabetes. Diabetes Obes Metab. 2019 Jun;21(6):1399-o8. [PMID: 30761720]

[25] Aroda VR, González-Galvez G, Grøn R, Halladin N, Haluzík M, Jermendy G, Kok A, Őrsy P, Sabbah M, Sesti G, Silver R. Durability of insulin degludec plus liraglutide versus insulin glargine U10o as initial injectable therapy in type 2 diabetes (DUAL VIII): a multicentre, open-label, phase $3 \mathrm{~b}$, randomised controlled trial. Lancet Diabetes Endocrinol. 2019 Aug;7(8):596-605. [PMID: 31189519]
[26] Xultophy 100/3.6(insulin degludec and liraglutide injection), for subcutaneous use [prescribing information]. [Cited 2020 Jan 20]. Available from: https://www.accessdata.fda.gov/drugsatfda_docs/labe 1/2016/208583sooolbl.pdf

[27] Cohen ND, Audehm R, Pretorius E, Kaye J, Chapman LH, Colagiuri S. The rationale for combining GLP-1 receptor agonists with basal insulin. Med J Aust. 2013 Aug 19;199(4):246-49. [PMID: 23984780]

[28] Tibaldi J, Mercado ME, Strong J. How Effective Is the Fixed-Ratio Combination of Insulin Degludec and Liraglutide (IDegLira) in Different Patient Populations, and When Should It Be Used in Clinical Practice?. Clinical Diabetes. 2020 May 22.

[29] Raya PM, Blasco FJA, Hunt B, Martin V, Thorsted BL, Basse A, Price H. Evaluating the long-term costeffectiveness of fixed-ratio combination insulin degludec/liraglutide (IDegLira) for type 2 diabetes in Spain based on real-world clinical evidence. Diabetes Obes Metab. 2019 Jun;21(6):1349-56. [PMID: 30740861]

[30] Kalra S, Das AK, Sahay RK, Baruah MP, Tiwaskar M, Das S, Chatterjee S, Saboo B, Bantwal G, Bhattacharya S, Priya G, Chawla M, Brar K, Raza SA, Aamir AH, Shrestha D, Somasundaram N, Katulanda P, Afsana F, Selim S, Naseri MW, Latheef A, Sumanatilleke M. Consensus Recommendations on GLP-1 RA Use in the Management of Type 2 Diabetes Mellitus: South Asian Task Force. Diabetes Ther. 2019 Oct;10(5):1645-17. [PMID: 31359367]

[31] Li X, Wu W, Wang Y, Zhang X, Feng X, Liu R. GLP1 Agonists Liraglutide Improved Vascular Endothelial Function in Type 2 Diabetes Rats. Diab Res Open Access. 2020 Aug 08;2(2):46-55. 